\title{
8avo

\section{Um olhar sobre diferentes perspectivas do design especulativo na produção especializada}

\author{
Bruno Augusto Lorenz; \\ Marco Lazzarotto; \\ Guilherme Corrêa Meyer; \\ Fabiane Wolff;
}

resumo:

O design especulativo é conceito presente nos estudos em design, mas que mostra fragilidades, seja pela falta de concordância entre os autores sobre o uso de um termo específico que descreva tais movimentos ou por um aparente elitismo que permeia tais práticas, isolando a discussão de outros campos do conhecimento. A fim de fortalecer e contribuir com a estruturação teórica do campo, este artigo busca identificar o que já foi publicado sobre o design especulativo. Por meio da técnica de revisão sistemática, pretende-se analisar os artigos indexados no portal de Periódicos Capes que carregam esse e outros termos relativos a tal prática. Busca-se então (i) compreender como os autores que citam o design especulativo em seus trabalhos entendem o termo, (ii) quais são os autores e referências que utilizam para justificar essa definição e, por fim, (iii) analisar como o design especulativo se relaciona com o contexto geral do que está sendo investigado nos trabalhos analisados. A busca considerou artigos publicados últimos 20 anos, em inglês, contendo as palavras chave "speculative design" AND "Dunne" em qualquer parte do texto. O sistema retornou 34 artigos revisados por pares a partir desses parâmetros. A primeira filtragem consistiu na leitura dos resumos desses trabalhos, resultando na manutenção de 22 artigos. O segundo filtro consistiu na leitura completa dos trabalhos - a fim de avaliar a pertinência dos escritos aos objetivos estabelecidos resultando em 17 artigos escolhidos para a análise final. A partir dessa análise, foi possível identificar que o design especulativo é visto como uma prática que potencializa o debate e expande o espaçoproblema por meio do desenvolvimento de artefatos. Além disso, a cooperação entre designers e cientistas permite que as descobertas feitas no âmbito acadêmico-científico possam ser levadas para a esfera pública a partir dos movimentos críticos e especulativos. A indefinição de termos vista no próprio campo se reflete nos artigos analisados, ainda mais quando se leva em consideração que o assunto é discutido por campos que vão de arquitetura e urbanismo, passando pela sociologia e tocando até mesmo áreas médicas.

palavras-chave: design especulativo; revisão sistemática; Anthony Dunne; 


\section{Introdução}

Antes de avançar ao problema de definição de nosso tema de estudo, o design especulativo, optamos por uma explicação fundamental. Ao invés de defini-lo, ou seja, apontar nossa compreensão sobre o que envolve o termo, preferimos ficar na superficialidade nesse primeiro momento. Assim, procuraremos torná-lo reconhecível tão somente para efeito de esclarecimentos que o texto requer. Furtamo-nos à imprescindível tarefa de definição por reconhecer no termo fragilidades que não recomendam (e talvez até impeçam) partir de uma definição única. Além disso, reconhecemos no esforço deste artigo, um interesse por avançar na literatura especializada como forma para tocar a pluralidade dessa definição desejada. Enfim, é tarefa a ser apreciada ao longo do texto.

Design especulativo é um termo que aborda a prática de projeto que se aproveita do desenvolvimento de artefatos $^{1}$ como uma forma de investigação essencialmente crítica e especulativa. Ao invés do enfoque habitual do design - comumente associado a resolução de problemas do mercado de consumo (ou design afirmativo, cf. Dunne e Raby (2013)) -, o design especulativo volta-se às discussões sobre a criação de futuros por meio da materialidade. $\mathrm{O}$ artefato construído, no entanto, não é o produto mais importante em um projeto de especulação. $\mathrm{O}$ que importa são as reflexões propostas a partir desse artefato, tanto pelos designers que o projetam, quanto pelo público que entra em contato com ele e o interpreta e reinterpreta continuamente. Nesse contexto, emergem métodos de projeto que transcendem a materialidade e voltam-se para dinâmicas discursivas, experimentais e críticas para alcançar seus objetivos (MALPASS, 2013). Tanto Malpass (2013), quanto Dunne e Raby (2013) não enxergam o design especulativo como uma oposição ao design afirmativo; para eles, são iniciativas que caminham próximas, em paralelo, com objetivos distintos: enquanto uma busca o ganho tecnológico ou financeiro, a outra enxerga o diálogo e a provocação como máximo valor.

As origens históricas desse movimento podem ser identificadas no radical design, movimento que floresce na década de 1960 e 1970, principalmente na Itália. Na época, designers como Andrea Branzi, Ettore Sottsass e Alessandro Mendini fundaram estúdios de design focados no desenvolvimento de ambientes, peças de mobiliário e produtos domésticos que exploravam qualidades estéticas e simbólicas, em detrimento de aspectos funcionais que marcavam os projetos da época (FIELL, FIELL, 2005).

O interesse acadêmico pelo tema, no entanto, se estrutura a partir dos anos de 1990. Em 1999, Dunne introduz o termo critical design no livro Hertzian Tales - Electronic Products, Aesthetic Experience, and Critical Design (DUNNE, 2005), produto de sua tese de doutorado. Neste trabalho fundante para a área, Dunne propõe "[...] uma abordagem que se utiliza do projeto de produtos eletrônicos conceituais como forma de provocar uma reflexão complexa e significativa sobre o ambiente ubíquo, desmaterializado e permeado por inteligência artificial em que vivemos" (DUNNE, 2005, p.xv). Posteriormente, Dunne e Raby (2013) adotam o termo speculative design, na obra Speculative Everything - Design, Fiction, and Social Dreaming. A dupla define o design especulativo como um caminho para gerar mudança os valores, crenças, atitudes e comportamentos da sociedade a fim de melhor enfrentar os problemas complexos enfrentados pela humanidade na contemporaneidade. Para os autores:

Esta forma de design prospera na imaginação e visa abrir novas perspectivas sobre o que às vezes são chamados de problemas capciosos, para criar espaços para discussão e debate sobre formas alternativas de ser e para inspirar e encorajar a imaginação das pessoas a fluir livremente. Projetos especulativos

\footnotetext{
${ }^{1}$ Artefato é entendido aqui de acordo com a perspectiva de Krippendorff (2006), que considera o artefato não apenas em sua materialidade, mas em todos os aspectos simbólicos que o mesmo pode carregar e comunicar. Dessa forma, o termo artefato engloba não apenas objetos físicos, mas também intangíveis (serviços, discursos, marcas, etc)
} 
podem atuar como um catalisador para redefinir nossa relação coletiva com a realidade $^{2}$ (DUNNE, RABY, 2013).

Um dos pontos que chama a atenção quando se estuda a área é sua indefinição quanto ao termo utilizado para descrever tais práticas. Design especulativo é um dos termos que se apresenta na literatura da área juntamente de muitos outros que abordam o mesmo assunto: design crítico, design conceitual, design interrogativo, design discursivo, design fiction, design provocativo, critical making, etc. Esse leque é problemático, tendo em vista que os termos se misturam e, muitas vezes, descrevem exatamente as mesmas práticas, o que conduz, invariavelmente, a usos incorretos e desentendimentos. Aos poucos, no entanto, surgem estudos dedicados ${ }^{3}$ a discutir definições taxonômicas específicas que dêem conta de diferenciá-los entre si, estruturando tal área do conhecimento.

Malpass (2013, p.334) também expressa preocupação com a natureza elitista da prática especulativa. Para o autor, há o risco de que ela torne-se "excessivamente auto-reflexiva e introvertida, sendo sustentada, praticada e alterada" por uma comunidade restrita de praticantes e estudiosos. Ainda mais quando se leva em consideração que os resultados de tais práticas, geralmente, são apresentados em museus e mostras de arte, restringindo o alcance das questões levantadas nos trabalhos. Preocupação semelhante é compartilhada por Dunne e Raby $(2001 ; 2013)$, quando estes argumentam que o design deve estabelecer uma postura intelectual sólida por meio da crítica e da reflexão, para que ele não seja visto apenas como uma mera ferramenta utilizada pela indústria para ganhos financeiros ou fins puramente estéticos. Para Malpass (2013), a prática crítica aparece na literatura paralelamente a campos como o codesign, o design social e o design participatório. Essas últimas, no entanto, se estabeleceram política e intelectualmente, outorgando ao designer o papel de facilitador em processos que buscam enfrentar problemas sociais complexos. O autor argumenta que a prática crítica, ao contrário dessas anteriormente citadas, ainda não foi absorvida pela "ortodoxia disciplinar" do design, tendo em vista uma aparente falta de esforço compartilhado de teóricos, comentaristas e praticantes da prática crítica/especulativa (MALPASS, 2013, p.335). Ou seja: é latente a necessidade de trabalhos acadêmicos e atividades de prática que dêem conta de preencher as lacunas teóricas do campo e estruturá-lo para que ele seja considerado com seriedade dentro da pesquisa em design.

Dessa forma, o presente artigo busca compreender (i) como os autores que incluem o design especulativo em seus trabalhos entendem o termo, (ii) quais são os autores e referências que utilizam para justificar essa definição e, por fim, (iii) analisar como o design especulativo é relacionado com o contexto geral do que está sendo investigado nos trabalhos analisados.

Feita a apresentação do tema e dos objetivos, segue a apresentação método utilizado aqui. Posteriormente, os resultados são expostos e discutidos e, por fim, as considerações finais são desenvolvidas.

\section{Método}

O presente artigo se utiliza da técnica de análise sistemática. Para Siddaway (2014), análises sistemáticas são caracterizadas pela objetividade, transparência e pela possibilidade de replicação do estudo. Um processo dessa natureza preocupa-se em localizar estudos que respondem a uma questão específica de pesquisa, apresentando também de maneira sistemática uma síntese das características e dos achados resultantes de tal busca (ibid., 2014).

Khan et al. (2003) explicam que uma análise sistemática rigorosa é desenvolvida por meio de um método composto por cinco passos (entre parênteses, como se deram os passos no presente artigo): (1) enquadramento da questão a ser investigada, neste caso, o design especulativo e seu entendimento por outras áreas do saber; (2) identificação de trabalhos relevantes, aqui desenvolvida com a busca por artigos no Periódicos Capes, em inglês, no período de 1997 a 2007; (3) avaliação da qualidade dos estudos, indicada pela escolha dos periódicos revisados por pares e posterior análise detalhada dos

\footnotetext{
${ }^{2}$ Do original: "This form of design thrives on imagination and aims to open up new perspectives on what are sometimes called wicked problems, to create spaces for discussion and debate about alternative ways of being, and to inspire and encourage people's imaginations to flow freely. Design speculations can act as a catalyst for collectively redefining our relationship to reality." (DUNNE, RABY, 2013)

${ }^{3}$ MALPASS, 2013
} 
textos) (4) resumo das evidências, descrito nos resultados desenvolvido nos itens da Discussão e das Considerações Finais.

(5) interpretação dos achados,

Ao considerar o trabalho de Dunne de 1999 como um marco da pesquisa na área e, portanto, como ponto de partida das buscas a serem realizadas, o período de tempo foi estabelecido em 20 anos. Dessa forma, é possível cobrir todo o período de pesquisa no campo. Para entender como as produções se distribuem temporalmente, foram realizadas pesquisas em diferentes recortes de tempo: dez, cinco e dois anos. As buscas foram realizadas tendo o Portal de Periódicos Capes como fonte.

As palavras chaves utilizadas foram speculative design e Dunne. Como citado anteriormente, são diversos os termos utilizados para descrever essa prática. Assim, o termo speculative, foi definido como principal para as buscas tendo em vista a adoção deste por Dunne (2013), em seu trabalho mais recente sobre o assunto. Além disso, dado que, em inglês, os termos speculative e design podem ser utilizados em diferentes contextos que não interessam aos problemas estabelecidos aqui, o termo Dunne foi inserido por entender que, nos artigos da área, o autor seria referenciado em algum momento, dado seu destaque nas produções do campo. Assim, os achados se limitam apenas a artigos que discutem o termo nos parâmetros desejados ${ }^{4}$. A partir desses parâmetros, o sistema apresentou 34 artigos revisados por pares. A tabela 1 reúne os resultados das buscas.

Tabela 1 - Caminho percorrido para delimitação dos artigos a serem analisados

\begin{tabular}{|c|l|l|l|l|}
\hline $\begin{array}{c}\text { Total revisado por } \\
\text { Pares }\end{array}$ & Idioma & Palavras Chaves & Tempo & Fonte \\
\hline 34 & inglês & "speculative design" AND "Dunne" & 20 anos & Periódicos Capes \\
\hline 34 & inglês & "speculative design" AND "Dunne" & 10 anos & Periódicos Capes \\
\hline 31 & inglês & "speculative design" AND "Dunne" & 5 anos & Periódicos Capes \\
\hline 24 & inglês & "speculative design" AND "Dunne" & 2 anos & Periódicos Capes \\
\hline
\end{tabular}

Fonte: os autores, baseado na pesquisa realizada.

A partir desses resultados, a condução da análise foi realizada da seguinte forma: (a) filtragem inicial, que considerava apenas artigos científicos revisados por pares; (b) leitura do resumo dos artigos; (c) triagem dos artigos que apresentavam alguma relação com os temas propostos, o que resultou na manutenção de 22 artigos. Sete foram excluídos por se tratarem de capítulos de livro, resenhas, artigos de opinião, erro no DOI ou por não apresentarem relação alguma com o tema; (d) leitura dos artigos completos para identificação das informações desejadas; (e) filtragem de artigos que apresentavam o design especulativo (ou conceitos relacionados) sem ligação com o tema central do trabalho, resultando em 17 artigos escolhidos para a análise final. Aqui, 5 foram excluídos pois citavam o design especulativo (ou termos relacionados) de maneira superficial, sem definir com clareza o termo a partir de algum autor ou sem associá-lo de alguma forma ao tema principal do artigo. A tabela 2 apresenta a quantidade de artigos selecionados pelo ano das publicações.

\footnotetext{
${ }^{4}$ Uma das fragilidades encontradas está em questões relacionadas a problemas na indexação de artigos pelo portal da Capes. A ausência de um dos poucos artigos presentes no periódico Design Issues (qualis A2) que tem o design especulativo como principal foco de debate (OLIVEIRA; 2016) exemplifica essa questão: nas buscas simples a partir das palavras chaves "speculative design" AND "Dunne", o artigo figura nos resultados. No entanto, quando a busca avançada é ativada para limitar as buscas a (i) artigos (ii) em inglês (iii) dos últimos 20 anos, o artigo não é listado, mesmo que ele atenda a todos os parâmetros descritos acima. Outros artigos pertinentes sofrem do mesmo problema (AUGER, 2013; DISALVO, 2012; FORLANO, MATHEW, 2014). Na ocasião da pesquisa, os autores entraram em contato com a biblioteca da instituição relatando o problema, que também não encontrou uma justificativa plausível sobre a ausência dos trabalhos nos resultados. É importante observar, no entanto, que a falta de tais artigos não afeta a qualidade do trabalho desenvolvido aqui, tendo em vista que os objetivos propostos tratavam de um recorte específico e não exaustivo.

${ }^{5}$ Essa etapa foi necessária também para filtrar materiais como capítulos de livros e artigos de opinião. Um dos filtros do sistema limitava a busca apenas a artigos revisados por pares. No entanto, ao efetuar o download, alguns dos materiais não se encaixavam nessa categoria.
} 
Tabela 2 - Artigos selecionados para o estudo

\begin{tabular}{|c|c|c|c|}
\hline $\begin{array}{c}\text { Artigos selecionados para } \\
\text { o estudo }\end{array}$ & Total de resumos selecionados & $\begin{array}{c}\text { Total de artigos encontrados pela } \\
\text { ferramenta de busca }\end{array}$ & Ano \\
\hline 0 & 0 & 0 & 1997 a 2007 \\
\hline 0 & 0 & 0 & 2008 \\
\hline 0 & 0 & 2 & 2009 \\
\hline 0 & 0 & 0 & 2010 \\
\hline 1 & 1 & 1 & 2011 \\
\hline 2 & 2 & 2 & 2012 \\
\hline 1 & 1 & 2 & 2013 \\
\hline 2 & 2 & 3 & 2014 \\
\hline 3 & 5 & 8 & 2015 \\
\hline 6 & 7 & 9 & 2016 \\
\hline 2 & 4 & 6 & 2017 \\
\hline 0 & 0 & 1 & sem data \\
\hline 17 & 22 & 34 & TOTAL \\
\hline
\end{tabular}

Fonte: elaborado pelos autores, com base na pesquisa realizada

Após realizada uma leitura completa, para entender o contexto geral de cada um dos trabalhos analisados, os movimentos foram os seguintes: (a) busca no arquivo pela palavra design, a fim de identificar conceitos próximos e pertinentes relacionados ao termo: speculative, critical, conceptual, reflective, interrogative, provocative, etc; (b) ao localizar tais conceitos, registrar qual é a definição dada pelos autores (c) compreender como o conceito se relaciona com a proposta geral do artigo.

Deste modo, os artigos são apresentados a seguir de modo cronológico e discutidos posteriormente a partir de categorias que emergiram a partir da análise dos textos, a saber: (a) modo alternativo de processo que opera na exploração de outras perspectivas do problema; (b) posicionamento crítico sobre dinâmicas sociais correntes e sobre questões de ordem moral e ética; (c) modo de imaginar o futuro, e propor crítica sobre como o mundo deveria ser; (d) modo de explorar possibilidades de ressignificação e aplicação de produtos e técnicas, o que envolve, por exemplo os estudos sobre como os artefatos afetam os humanos; (e) modo de engajamento e imaginário social de públicos diversos; (f) modo abrangente de avançar na compreensão da relação da humanidade e tecnologia e ciência.

\section{Resultados}

Aqui descrevemos os resultados alcançados a partir dos critérios apresentados na seção anterior. Optamos por apreciar os textos e resgatá-los um a um, o que foi tanto possível pela quantidade de textos selecionados quanto desejável para que se alcançasse suas especificidades.

Bowen e Petrelli (2011), apresentam o conceito de digital memento para que, junto com a ideia de artefatos críticos para apreciação do registro de memórias, os autores possam compreender de que maneira as pessoas podem se envolver com projetos que lhes permitam lembrar de momentos específicos de suas vidas e de como isso pode ser particularmente engajador. Os resultados da pesquisa envolvem propostas de mementos digitais, levando em conta os entendimentos que designers e os pesquisadores obtiveram com a pesquisa, em que se pese as práticas, necessidades e valores das pessoas pesquisadas. O design crítico é entendido como um elemento chave para a criação de engajamento. Os autores consideram a ótica de Dunne e Raby (2001), em que o design crítico se distingue como uma alternativa ao design afirmativo, pois aquele não produz objetos para venda ou troca, mas estimula reflexões nos públicos. O design crítico utilizaria então propostas especulativas (nos termos de Dunne) como forma de desafiar presunções, preconceitos e lugares comuns sobre os papéis que os produtos têm no dia-a-dia das pessoas.

Michael (2012a; 2012b), discute o potencial de idiotice proativa do design especulativo. Idiota, na discussão apresentada pelo autor, é uma personagem conceitual que, por não compreender as situações em que é colocado, não responde a tais situações da maneira como todos os outros responderiam. Tal atitude sugere uma visão diferente do mundo habitual, o que se conversa com os princípios do design especulativo. Nessa lente, artefatos idiotas são projetados com funções oblíquas e 
ambíguas que permitem que tanto usuários quanto designers possam explorar temas de maneiras mais livres, criativas e generativas. Assim, artefatos especulativos permitem que termos como "vizinhança" ou "redução na demanda de energia" possam ser entendidos sobre diferentes perspectivas, em um movimento de "criação inventiva de problemas". Para o autor, existe uma separação entre o design crítico e o design especulativo. O design crítico - associado às práticas de Dunne - não é "idiota" pois ele se apoia em uma crítica muito específica, onde o problema já se encontra claro e bem estruturado. $\mathrm{O}$ design especulativo (associado aos projetos de Gaver), por outro lado, desenvolve objetos funcionais que buscam provocar reflexões sobre o papel complexo que novas tecnologias interpretam na sociedade. Michael explica que o design especulativo se diferencia do design crítico pois o engajamento dos públicos que utilizam os objetos faz parte da própria significação e ressignificação do artefato. Dessa forma, esse objeto é constantemente modificado - formal e semioticamente. Michael (2012b) propõe uma "Pesquisa Ação Lúdica" (PAL), em que pesquisa-ação se aproveita dos conceitos de abertura, incerteza e playfulness do design especulativo para enxergar os problemas sociais de outras perspectivas. Ao invés de identificar problemas e implementar soluções, a PAL busca a abertura das possibilidades, revisando tais problemas e reimaginando a relação dos envolvidos com tais problemáticas.

Damm et al. (2013) refletem sobre a biologia sintética e como a arte e o design podem aproveitar desses avanços para se posicionar criticamente em relação aos impactos culturais e sociológicos de tais tecnologias. Assim, é analisada a atuação de um grupo de estudantes que trata de discussões provocativas sobre biologia sintética, biotecnologia e bioarte, em um movimento que une designers e cientistas - tudo por meio do design crítico e do design para debate, ambos tendo Dunne e Raby como referência. Os autores argumentam que a colaboração entre tais agentes é benéfica, a partir do momento em que produtos especulativos são criados para tornar mais palatável e claro o impacto de tecnologias futuras para o grande público.

Catts e Zurr (2014) relacionam o desenvolvimento de produtos de aplicação em ciências biológicas e médicas na criação de produtos de consumo, arte e design. O trabalho aborda como descobertas com carne e couro in-vitro são aproveitadas em projetos de design especulativo e práticas artísticas contemporâneas. A mudança de paradigma de manufatura se dá no movimento de construir (building) para cultivar (growing) e passa-se então a especular quais seriam as aplicações possíveis e desejáveis para o campo. A partir daí, os autores trazem construtos de design e arte que passam por este tipo de cultivo artificial (como a orelha nas costas do rato, um dos mais lembrados casos de desenvolvimento de engenharia de tecidos vivos) até casos mais recentes de projetos in vitro que trazem elementos de design, arte e ciência com propósitos críticos. O objetivo é discutir como estes artefatos podem ser usados como ferramentas de produção e expressão cultural.

Ikemiya e Rosner (2014) refletem sobre como o processo de degradação de objetos pode ser ressignificado - influenciando seu uso ou como é percebido simbolicamente, por exemplo - e como tais processos podem ser utilizados para permitir uma prática de projeto mais responsável e reflexiva. Por meio de abordagens do design crítico e especulativo, fundamentadas em Gaver, Sengers e Hutchinson, os autores desenvolveram uma série de artefatos que poderiam ser quebrados, amassados e colados para, posteriormente, serem alvo de discussões e reflexões sobre os novos significados que emergem dessas intervenções.

Anderson (2015) faz uma crítica à maneira como os designers e artistas usam o design especulativo e crítico como forma de abordar o Antropoceno $^{6}$ dentro de uma dimensão cultural, em que se discute as formas como a humanidade se relaciona com tecnologia e ciência, como se define política e socialmente e como se organiza dentro de uma expectativa de ambiente ecológico. A artista se utiliza da análise de obras e artefatos de designers e artistas que buscam trazer consciência para a situação ecológica atual e as perspectivas criadas pelo Antropoceno, um movimento interdisciplinar que acaba por provocar discussões relacionadas ao pós-humanismo, antropodocentrismo e pensamento orientados para o objeto versus pensamento vital materialista. A autora reforça o conceito da disciplina ao estipular que, porque o "design especulativo e crítico é uma forma de fazer para facilitar o pensar

\footnotetext{
${ }^{6} \mathrm{O}$ Antropoceno é uma tese científica corrente, criada pelo ganhador do Nobel e químico holandês Paul Crutzen que discorre sobre uma nova era geológica atual para o planeta, em que os efeitos do homem na paisagem terrestre e no clima já são sentidos a ponto de serem irreversíveis. O Antropoceno substituiria o Holoceno (iniciado há mais de 11 mil anos) como Era Geológica atual.
} 
ele é a melhor maneira de endereçar um assunto como o Antropoceno" (ANDERSON, 2015, pp. 2). Ainda segundo a autora os projetos descritos e debatidos no artigo são desconfortáveis, porque tocam em pontos e problemas reais, não se entregando a soluções fáceis mas antes postulando reimaginações radicais, convidando para uma visão de futuros radicais.

Nold (2015) relaciona o design crítico e o design especulativo com um tema urbanístico, $o$ Urban computing. Essa área enxerga os espaços urbanos como uma plataforma: um ambiente em que as práticas digitais dos habitantes da cidade geram uma quantidade enorme de dados que influencia os elementos físicos da cidade, de forma que esta se transforma em um campo de desenvolvimento tecnológico e de experimentação. $\mathrm{O}$ autor associa a Teoria Ator Rede de Latour ao design crítico quando argumenta que o os objetos críticos influenciam os atores humanos quando os convidam a serem protagonistas no processo de sua significação. Nesse sentido, Nold (2015) busca entender como objetos podem afetar pessoas para que se tornem conscientes dos problemas que a cercam. Para o autor, a resposta está no desenvolvimento de artefatos criados a partir do princípio de escala sóciotécnica, o que permite o engajamento de novos atores e a construção de materiais públicos. "O design crítico e o design especulativo propõe objetos normativos que têm um poder de engajamento em um nível emocional profundo, além de propor futuros alternativos" (NOLD, 2015, p.8)

Holmer, DiSalvo, Sengers e Lodato (2015) abordam as interações entre humanos e computadores (Human Computer Interactions - HCI) e de que maneira designers e artistas podem incentivar participação e engajamento dos públicos com artefatos desenvolvidos para elicitar este tipo de interação com propósitos variados. Isso é feito por meio do estudo de caso de algumas instalações feitas em festivais de design e arte, especialmente os que solicitaram a participação do público em uma espécie de co-uso. $\mathrm{O}$ trabalho oferece ainda três estratégias para que os projetistas possam ter respostas diferentes e desejadas do público: com participação na exibição (spectacle), participação no fazer (making) e participação na crítica (inquiry). Segundo os autores na sua conclusão, há o risco que a pesquisa e desenvolvimento em HCI fique à margem e acabe por alienar a participação do público. Com as três estratégias propostas a pesquisa com e por meio de HCI pode conseguir a checagem e o equilíbrio necessários para conseguir fazer aquilo que é mais essencial na criação de sistemas que prototipam futuros possíveis: a participação de não-designers.

Strachan (2016) trata da ligação do design especulativo e crítico (Speculative and Critical Design - SCD) com a área médica. O autor (ibid., p. 16) argumenta que "o que diferencia o SCD de outras disciplinas de design é o fato de que seus "produtos" - ou resultados - são artefatos provocativos projetados não para serem funcionalmente úteis, mas que se voltam para uma atitude de "design para debate". Quando combinados com a ferramenta de cenários, os artefatos especulativos buscam levantar questionamentos relacionados ao impacto das novas tecnologias na política, na economia, nos sistemas sociais e até mesmo nos valores e no comportamento da sociedade. $\mathrm{O}$ autor enumera quatro limitações da SCD: (1) a tendência de considerar apenas problemas de primeiro mundo que afeta uma minoria de ocidentais ricos; (2) a falta de engajamento, tanto dos processos quanto dos resultados; (3) a fetichização das tecnologias em detrimento de outras alternativas e (4) a falta de vontade de tomar decisões - ou projetos - difíceis que encorajem mudanças. Strachan (2016) apresenta três estudos de casos que constroem pontes entre o design e a medicina, além de demonstrar a pluralidade do design como provocação, como engajamento e como crítica social. Ao associar o SCD com metodologias próprias do Design Participatório, o autor enxerga que tal prática permite que designers, médicos, terapeutas, pacientes, acadêmicos e população possam pensar coletivamente o futuro e reimaginá-lo criticamente, na busca de diferentes futuros desejáveis.

Lindley e Sharma (2016) explora a ética e as complexidades da tecnologia de forma pouco usual: um documentário produzido pelo viés do design ficcional. A película especula sobre o papel de robôs cuidadores na vida de pessoas idosas a partir de uma série de entrevistas feitas com pessoas que relatam suas experiências com as máquinas. Além das entrevistas, a obra se aproveita de trechos de um filme lançado em circuito comercial - Robot and Frank -, sendo este tratado pelos pesquisadores como "uma peça acidental de design ficcional". Para os autores, o design ficcional se aproveita de um pensamento especulativo para imaginar o futuro através da criação de artefatos que se manifestam de diversas maneiras: filme, textos, objetos ou até mesmo uma combinação de todos eles. Tendo como referência diferentes autores - Auger, Sterling, Dunne e Kirby -, Lindley e Sharma (2016) propõem um método de pesquisa chamado de Etnografia Antecipatória, que propõe o uso de peças de design ficcional como parte fundamental de projetos de pesquisa etnográfica. 
Vaage (2016) discute como obras de arte criadas com técnicas oriundas da biotecnologia levantam questões éticas importantes, já que tais obras utilizam materiais vivos nos trabalhos. A autora apresenta brevemente o design especulativo como uma alternativa para debater as mesmas questões éticas, sem a necessidade de utilizar técnicas bio-científicas e fazer uso de organismos vivos. Uma das falas da autora revela outra vantagem do design especulativo: a capacidade de expandir o espaçoproblema e as discussões que florescem nele. "Os trabalhos de bioarte e os comentários do público podem desempenhar um papel na ampliação ou na restrição dos campos de possibilidades de que os artistas estão tentando criar consciência, influenciando as futuras decisões sobre o que a nossa sociedade deveria ser." (VAAGE, p.101)

Johung (2016) também aborda questões de biotecnologia e de como formas de vida orgânicas ganham modificações sintéticas que reorganizam e redirecionam seu desenvolvimento. A autora relaciona as mudanças no campo da biotecnologia e das formas de vida sintética com o campo do design especulativo, em que propostas críticas e às vezes radicais direcionam o mundo como o conhecemos para uma vida como ela deveria ser. Desta maneira o design passa de um "processo eficiente de resolução de problemas para uma ferramenta exploratória de descoberta de problemas" (JOHUNG, 2016, pp. 7).

Lodato e DiSalvo (2016) se utilizam de relatos etnográficos para explorar como hackathons $^{8}$ são estruturados e quais são as formas interação e participação que emergem nesses eventos. Nas conclusões, os autores argumentam que as manifestações materiais dos projetos - os protótipos - se aproximam de uma lógica de prática especulativa que contribui para o "imaginário social". Para eles: "Por meio do processo de conceitualização e produção, os participantes de hackathons abordam a imaginação coletiva sobre como futuros usuários podem participar em questões por meio de adereços que os participantes estão construindo" (ibid., p.16). Ao explicar o conceito de design especulativo como uma forma de "social dreaming" - quando questões provocativas sobre o futuro evocam reflexões sobre como eles poderiam se manifestar -, os autores defendem que hackathons funcionam de maneira similar, visto que o desenvolvimento dos protótipos expressa a possibilidade e o potencial de ação com relação a problemas ou públicos específicos.

Küpers (2016) discute o design como uma prática transformadora, que ressignifica as práticas éticas, sociais e economicamente obsoletas que "danificam" o planeta. Cita Anderson (2015) como referência para o design especulativo, sugerindo que este funciona como uma prática que oferece "[...] vias para analisar a complexidade da situação[...]", ao sugerir uma abordagem crítica que se volta para a construção de cenários futuros radicais nas práticas sustentáveis. O autor relaciona o design especulativo com o que ele chama de artful designs fictions. Em sua discussão, Küpers (2016) cita Dunne (1999) ao apresentar a possibilidade do artful design fiction oferecer uma visão utópica - porém pragmática - que contribui para experiências futuras sustentáveis.

Candy e Dunagan (2016) fazem uma introdução que propõe distinguir entre o conceito de futuros experiênciais e cenários experiênciais, onde a distinção aparece principalmente na forma em que os futuros experiênciais têm foco na criação de um "guarda-chuva para a prática" (Candy e Dunagan, 2016, pp. 2) e os cenários com um resultado de um método em particular. Essa distinção é preliminar e se aprofunda durante o trabalho com os conceitos de design especulativo e design ficcional. De acordo com os autores, além das introduções aos conceitos, já se faz necessária um modelo de registro, análise e demonstração de como os projetos de design especulativo impactam os envolvidos. Desta forma, o trabalho se torna um método de avaliação do processo (incluindo o processo de co-criação dos projetos) e também uma provocação para que se façam abordagens de avaliação sistemática para todo o processo de instrumentação nos modelos apresentados. Isso é feito por meio de uma análise da presença de códigos repetidos encontrados em diversos artefatos criados

\footnotetext{
${ }^{7}$ Do original: "Bioartworks, and commentaries from the audience, can play a role in widening or tightening the fields of possibility that artists are trying to create awareness of, thus potentially influencing future decisions as to what our society should be like." (p.101)

${ }^{8}$ Hackathons são eventos de prototipação rápida em que voluntários se unem para conceituar, prototipar e construir produtos e serviços (cf. LODATO; DISALVO; 2016).
} 
pela humanidade, chamado pelos autores de "The People Who Vanished", um experimento de entendimento por meio de co-design e design crítico, usando elementos do design especulativo para o modelo. Entre os resultados apresentados pelos pesquisadores é a asserção de que um dos desafios centrais do design para o futuro é "menos projetar (gerar) e comunicar ideias sobre o futuro e mais projetar circunstâncias e situações em que a inteligência coletiva e a imaginação da comunidade possam vir à tona" (CANDY E DUNAGAN, 2016, p.15).

Kemp (2017) discute o papel do design em moldar o futuro partindo da análise dos programas educacionais e das práticas de coleção dos museus britânicos de artes industriais no séc. XIX. Para isso a autora examina as dinâmicas históricas entre as construções de futuro nos conhecimentos de design, e conclui com forças potenciais de agência social e ativismo para que se promova uma reflexão crítica nos métodos que as instituições sociais formulam as direções de mudança. O design especulativo aparece à margem do trabalho, com presença nas estratégias dos museus para a imaginação dos futuros. Isso acontece por causa das "amplas funções cognitivas e discursivas do design" (KEMP, 2017, pp. 3), e por meio das ricas maneiras de construção de conhecimento com storytelling, design ficcional e design especulativo, que têm um papel importante de construir processos sociais e intelectuais de crítica por meio de novas abordagens de apresentação e novos formatos de exibição.

\section{Discussão}

Procuraremos apresentar a discussão do trabalho a partir da estrutura proposta no método: (i) como os autores que incluem o design especulativo em seus trabalhos entendem o termo, (ii) quais são os autores e referências que utilizam para justificar essa definição e, por fim, (iii) analisar como o design especulativo é relacionado com o contexto geral do que está sendo investigado nos trabalhos analisados.

No que diz respeito a maneira como os autores estudados tratam o design especulativo, é interessante perceber algumas diferenças significativas. Entre as pesquisas, identificamos no conceito: (a) modo alternativo de processo que opera na exploração de outras perspectivas do problema (MICHAEL, 2012a, 2012b); (b) posicionamento crítico sobre dinâmicas sociais correntes (DAMM ET AL., 2013; STRACHAN, 2016) e sobre questões de ordem moral e ética (VAAGE, 2016); (c) modo de imaginar o futuro (LINDLEY E SHARMA, 2016; CANDY E DUNAGAN, 2016; KEMP, 2017), e propor crítica sobre como o mundo deveria ser (JOHUNG, 2016; KÜPERS, 2016); (d) modo de explorar possibilidades de ressignificação (IKEMIYA E ROSNER, 2014) e aplicação de produtos e técnicas (CATTS E ZURR, 2014), o que envolve, por exemplo os estudos sobre como os artefatos afetam os humanos (NOLD, 2015); (e) modo de engajamento (HOLMER ET. AL, 2015) e imaginário social (LODATO E DISALVO, 2016) de públicos diversos; (f) modo abrangente de avançar na compreensão da relação da humanidade e tecnologia e ciência (ANDERSON, 2015).

Tal quadro de distinção aponta para (1) à própria ambivalência inerente às propriedades do conceito de especulação; (2) à uma eventual incompreensão ou uso indevido do conceito nas pesquisas analisadas; (3) às possibilidades de abertura e ampliação de um conceito recente e paulatinamente incorporado às práticas de design e áreas correlatas.

Sobre os autores e referências utilizadas, é necessário enfatizar que esta pesquisa precisou lidar com uma limitação quanto aos filtros aplicados na escolha dos artigos. Mais especificamente, optamos por trabalhos que mencionassem o autor Dunne, por reconhecer nele um elemento de corte significativo, dada sua posição de protagonista. Tal escolha traz implicações, evidentemente. Uma delas, a de restringir outros estudos que tratem de especulação mas que mencionem esse autor escolhido. Ainda assim, percebemos autores como Sengers e Gaver (2006); Gaver et al. (2008); Auger (2013); DiSalvo (2012) sendo referenciados nos estudos.

No que diz respeito à forma como o design especulativo é relacionado ao contexto geral das pesquisas, podemos perceber diferentes formas de relação. Por exemplo, chama atenção a variedade de

\footnotetext{
9 “Aqueles Que Desapareceram" (em tradução livre) se refere a uma tribo que existiu milênios antes da chegada de colonizadores europeus no que é hoje a cidade de Phoenix, no Arizona. A tribo teve impacto importante no panorama ecológico da época (1.400 a.C.) mas desapareceu sem vestígios, assombrando arqueólogos.
} 
autores que buscam no design especulativo uma possibilidade de enxergar o seu próprio campo por uma nova perspectiva: arquitetura e urbanismo (NOLD, 2015), "medical humanities" (STRACHAN, 2016), sociologia (MICHAEL, 2012a; MICHAEL, 2012b) ética e biotecnologia (VAAGE, 2016). Essa pluralidade reflete em parte o potencial do design especulativo indicado por Malpass (2013). Para o autor, este é um campo de prática e pesquisa que não deve se fechar em si, sendo confinado e resumido a discussões que consideram apenas os designers. A variedade de pesquisadores de outras áreas que abraçam o design especulativo é um indicativo da abrangência do conceito.

No que diz respeito à abrangência do conceito, futuras pesquisas podem avançar em outros campos ainda inexplorados. Por exemplo, o potencial especulativo de certas práticas de design foi utilizado entre as pesquisas estudadas, mais especificamente o trabalho de Michael (2012a, 2012b), como modo de adivinhar outras perspectivas para se lidar com os problemas de design. Acreditamos que a especulação, quando ampliada a partir do sentido explorado por Michael, pode figurar no campo das possibilidades, isto é, dissociando-se fundamentalmente de qualquer perspectiva que tenha o problema como foco. Assim, poderia-se investigar de que forma a especulação torna-se recurso para repensar os processos de design, para além dos espaços de problema ou solução.

\section{Considerações Finais}

A partir das análises, é possível afirmar que o design especulativo é visto pelos autores de outras áreas sob diferentes óticas: algumas delas já observadas pelos teóricos do campo, outras que sinalizam emergências que podem ser potencializadas e melhor exploradas. A materialização de visões de futuro utópicos e desejáveis (e.g. KÜPERS, 2016); a busca por engajamento público para discussão de tais visões (e.g. MICHAEL, 2012a); a construção de artefatos para desafiar presunções (e.g. BOWEN E PETRELLI, 2011), e pré conceitos comuns sobre objetos do dia a dia (e.g. IKEMIYA E ROSNER, 2014) são algumas das qualidades que os pesquisadores enaltecem sobre a prática especulativa. A capacidade de tais movimentos especulativos servirem para ampliar o espaço-problema investigado também merece destaque (e.g. VAAGE, 2016). Nessa visão, conceitos centrais da investigação podem ser tocados ou ressignificados a partir de um artefato que problematiza o que se tem como uma certeza dentro do projeto de pesquisa. Nos artigos que tratam a tecnologia como tema central, os autores destacam as vantagens de movimentos colaborativos entre designers e cientistas (e.g. DAMM ET AL., 2013; STRACHAN 2016), em que o design especulativo pode servir como uma forma expressão e produção cultural, comunicando as descobertas feitas no laboratório para o cotidiano da população.

Sobre o uso dos termos, não foi possível identificar a preferência dos pesquisadores por um termo específico que defina o campo. Em diversos artigos (e.g. MICHAEL, 2012; NOLD, 2015; VAAGE, 2016), termos diferentes são utilizados para descrever exatamente as mesmas práticas, muitas vezes, tendo como base o mesmo referencial teórico. Essa era uma confusão já era esperada pelos autores, tendo em vista que mesmo entre os pesquisadores do campo tais definições ainda não estão alinhadas. Nesse sentido, cabe a designers e pesquisadores que investigam o design crítico e especulativo a tarefa de organizar uma taxonomia que dê conta dos diferentes aspectos - tais como os apresentados ao longo da pesquisa. Tal movimento é necessário, acreditamos, para consolidar o campo e possibilitar ainda mais apreensões do mesmo por outras áreas de conhecimento.

Com relação ao período de tempo em que os artigos foram publicados, destaca-se a atualidade das publicações. Apesar do termo ter sido apresentado por Dunne há cerca de 20 anos atrás, somente nos últimos cinco anos que cresce o volume de trabalhos que abordam o design especulativo e suas ramificações, sendo que os últimos três anos reúnem $64 \%$ dos artigos selecionados na presente pesquisa. Tal fator pode estar associado à percepção (relativamente recente) da área sobre a insuficiência dos modelos de processo de design orientados pela concepção de problema-solução. Nesse caso, como dissemos, o componente especulativo surge como alternativa potencial. Ou melhor, a comunidade acadêmica parece perceber no campo de especulação, somente mais recentemente, um modo alternativo para avançar na compreensão de seus processos.

Outro aspecto a ser ressaltado é o número de artigos que trazem exemplos de projetos de design que se valem da especulação crítica. Em dez dos 17 artigos selecionados figuram artefatos especulativos. Desses, quatro eram artigos que continham cases e referências e (e.g. VAAGE, 2016), em outras seis oportunidades (e.g. IKEMIYA E ROSNER, 2014), os artigos apresentavam projetos especulativos desenvolvidos especificamente para o trabalho. Identifica-se aí uma oportunidade para 
pesquisadores da área desenvolverem artefatos sob essa perspectiva, construindo pesquisas voltadas a reflexões e discussões sobre as particularidades e os conhecimentos gerados pelos artefatos. Isso aponta, também, para a especulação como elemento de pesquisas de base projetual (practice-based design research). Outras investigações poderiam ser desenvolvidas para avaliar o quanto outras temáticas tem se utilizado da ótica projetual (ou do desenvolvimento de artefatos) como forma de construção de conhecimento. Assim, a especulação poderia revelar uma prática de intervenção, que amplia o sentido de investigação das pesquisas convencionais descritivas.

\section{A Look At Different Perspectives Of Speculative Design In Specialized Academic Production}

Abstract: The Speculative Design is a concept present in design studies, but it shows frailties, either because of the lack of agreement among the authors about the use of a specific term that describes such concept or by an apparent elitism that permeates such practices, isolating the discussion from other fields of practice. In order to strengthen and contribute to the theoretical structuring of the field, this article seeks to identify what has already been published about speculative design. Through the technique of systematic review, we intend to analyze the articles indexed in the portal of Periódicos Capes (Periodical Capes) that carry this and other terms related to that practice. It is then sought (i) to understand how authors who cite speculative design in their works understand the term, (ii) what authors and references they use to justify this definition, and (iii) to analyze how the speculative design relates to what is being investigated in the works analyzed. The search considered articles published in the last 20 years, in English, containing the keywords "speculative design" and "Dunne" anywhere in the text. The system returned 34 peer-reviewed articles within these parameters. The first filtering consisted of reading the abstracts of these papers, resulting in the permanence of 22 articles. The second filter consisted of the complete reading of the papers - in order to evaluate the pertinence of the writings to the established objectives - resulting in 17 articles chosen for the final analysis. From this analysis, it was possible to identify that the speculative design is seen as a practice that potentiates the debate and expands the problem-space through the development of artifacts. In addition, the cooperation between designers and scientists allows that the discoveries that are made in the academic-scientific scope can be brought to the public sphere from the critical and speculative movements. The lack of definition of terms seen in the field itself is reflected in the analyzed articles, especially when one considers that the subject is discussed by fields ranging from architecture and urbanism, through sociology and even reaching the medical areas.

Keywords: speculative design; systematic review; Anthony Dunne;

\section{Referências Bibliográficas}

AUGER, J. Speculative design: crafting the speculation. Digital Creativity, v. 24, n. 1, p. 11-35, 2013.

ANDERSON, K. Ethics, Ecology, and the Future: Art and Design Face the Anthropocene. Leonardo, v. 48, n. 4, p. 338-347, 2015.

BOWEN, S.; PETRELLI, D. Remembering today tomorrow: Exploring the human-centred design of digital mementos. International Journal of Human Computer Studies, v. 69, n. 5, p. 324-337, 2011.

CANDY, S.; DUNAGAN, J. Designing an experiential scenario: The People Who Vanished. Futures, v. 86, p. 136-153, 2017. 
CATTS, O.; ZURR, I. Growing for different ends. International Journal of Biochemistry and Cell Biology, v. 56, p. 20-29, 2014.

DAMM, U. et al. Are artists and engineers inventing the culture of tomorrow? Futures, v. 48, p. 5564, 2013.

DISALVO, C. Spectacles and tropes: speculative design and contemporary food cultures. Fibreculture Journal 20: 109-121. 2012.

DUNNE, A. Hertzian tales: electronic products, aesthetic experience and critical design. London, UK: MIT Press, 2005.

DUNNE, A., Raby, F. Design Noir: The Secret Life of Electronic Objects. Basel: Birkhäuser, 2001.

DUNNE, A; RABY, F. Speculative Everything: Design, Fiction, and Social Dreaming. Cambridge; London: The Mit Press, 2013.

FIELL, C; FIELL, P. Design do Seculo XX. Köln: Taschen, 2005.

FORLANO, L.; MATHEW, A. From Design Fiction to Design Friction: Speculative and Participatory Design of Values-Embedded Urban Technology. Journal of Urban Technology, v. 21, n. 4, p. 7-24, 2014.

GAVER, W.; BOUCHER, A.; LAW, A.; PENNINGTON, S.; BOWERS, J.; BEAVER, J.; HUMBLE, J.; KERRIDGE, T.; VILLAR, N.; WILKIE, A. Threshold Devices: Looking Out From The Home. Proceeding of the 26th Annual SIGCHI Conference on Human Factors in Computing Systems, Florence, Italy, 1429-38. New York, NY: ACM Press. 2008.

HOLMER, H. B. et al. Constructing and constraining participation in participatory arts and $\mathrm{HCI}$. International Journal of Human Computer Studies, v. 74, p. 107-123, 2015.

IKEMIYA, M.; ROSNER, D. K. Broken probes: Toward the design of worn media. Personal and Ubiquitous Computing, v. 18, n. 3, p. 671-683, 2014.

JOHUNG, J. Speculative Life: Art, Synthetic Biology and Blueprints for the Unknown. Theory, Culture \& Society, v. 33, n. 3, p. 175-188, 2016.

KEMP, S. Design Museum Futures: Catalysts for Education. Futures, 2017.

KHAN, K. S. et al. Five steps to conducting a systematic review. Jrsm, v. 96, n. 3, p. 118-121, 2003.

KÜPERS, W. Phenomenology of embodied and artful design for creative and sustainable interpracticing in organisations. Journal of Cleaner Production, v. 135, p. 1436-1445, 2016.

KRIPPENDORFF, K. The Semantic Turn: A New Foundation for Design. New York: Taylor\&Francis, CRC Press, 2005.

LINDLEY, J.; SHARMA, D. Operationalising design fiction for ethical computing. ACM SIGCAS Computers and Society, v. 45, n. 3, p. 79-83, 2016.

LODATO, T. J.; DISALVO, C. Issue-oriented hackathons as material participation. New Media \& Society, v. 18, n. 4, p. 539-557, 2016.

MALPASS, M. Between Wit and Reason: Defining Associative, Speculative, and Critical Design in Practice. Design and Culture, v. 5, n. 3, p. 333-356, 2013.

MICHAEL, M. "What Are We Busy Doing?" Science, Technology, \& Human Values, v. 37, n. 5, p. 528-554, 2012a.

MICHAEL, M. De-signing the object of sociology: Toward an "idiotic" methodology. Sociological Review, v. 60, n. SUPPL. 1, p. 166-183, 2012b.

NOLD, C. Micro/macro prototyping. International Journal of Human Computer Studies, v. 81, p. 72-80, 2015.

OLIVEIRA, P. J. S. V. DE. Design at the Earview: Decolonizing Speculative Design through Sonic Fiction. Design Issues, v. 32, n. 2, p. 43-52, 1 abr. 2016. 
SENGERS, P.; Gaver, W. Staying Open to Interpretation: Engaging Multiple Meanings in Design and Evaluation. Proceedings of the 6th Conference on Designing Interactive Systems, University Park, PA, USA, 99-108. New York, NY: ACM Press. 2006

SIDDAWAY, A. What is a Systematic Literature Review and how do I do one. University of Stirling, p. 1-13, 2014.

STRACHAN, C. G.; BROWN, B.; CRAWFORD, P. Design, fiction and the medical humanities. Medical Humanities, v. 42, n. 4, p. e15-e19, 2016.

VAAGE, N. S. What Ethics for Bioart? NanoEthics, v. 10, n. 1, p. 87-104, 2016. 